\title{
A Review on Diagnostic Methods of Brucellosis
}

Minda Asfaw Geresu ${ }^{1^{*}}$ and Gezahegne Mamo Kassa ${ }^{2}$

${ }^{1}$ School of Agriculture, Animal and Range Sciences, Madda Walabu University, Bale-Robe, Ethiopia

${ }^{2}$ College of Veterinary Medicine and Agriculture, Addis Ababa University, Bishoftu, Ethiopia

*Corresponding author: Minda Asfaw Geresu, School of Agriculture, Animal and Range Sciences Course Team, Madda Walabu University, Bale-Robe, Ethiopia, Tel: +251910431505; E-mail: minda.asfaw@gmail.com

Rec date: Nov 19, 2015; Acc date: Mar 29, 2016; Pub date: Mar 31, 2016

Copyright: $\odot 2016$ Geresu MA, et al. This is an open-access article distributed under the terms of the Creative Commons Attribution License, which permits unrestricted use, distribution, and reproduction in any medium, provided the original author and source are credited.

\section{Abstract}

We reviewed different diagnostic methods of brucellosis in different livestock and humans. Bacteriological diagnosis, immunohistochemistry (an alternative technique for direct diagnosis) and different molecular methods for Brucella species genotyping are among the direct methods for diagnosis of brucellosis discussed in this review. The well-established indirect methods for diagnosis of brucellosis, serological and brucellin allergic skin tests were also critically conferred. Finally, for effective control and prevention of brucellosis around the world, the direct diagnostic methods are advised in order to develop vaccine against the circulating Brucella strain in the specific country.

Keywords: Allergic skin test; Brucellosis; Immunohistochemistry; Molecular tool; Serological tests

\section{Introduction}

Brucellosis is an ancient disease that can possibly be traced back to the 5th plague of Egypt around 1600 BC. Recent examination of the ancient Egyptian bones, dating to around $750 \mathrm{BC}$, showed evidence of sacroilitis and other osteoarticular lesions, common complications of brucellosis [1]. David Bruce isolated Brucella melitensis (B. melitensis) (Micrococcus melitensis at that time) in 1887 from the spleen of a British soldier who died from a febrile illness (Malta fever) common among military personnel stationed on Malta. For almost 20 years after isolation of $M$. melitensis, Malta fever remained a mystery and was thought to be a vector-borne disease until Themistocles Zammit accidentally demonstrated the zoonotic nature of the disease in 1905 by isolating $B$. melitensis from goat's milk. It was believed that goats were not the source of infection since they did not become ill when inoculated with Brucella cultures. The discovery that healthy goats could be carriers of the disease has been termed one of the greatest advances ever made in the study of epidemiology $[2,3]$.

Brucellosis is caused by Gram-negative coccobacilli of the genus Brucella [4,5]. In livestock, the disease results in significant economic losses due to reproductive impairment caused by abortion, stillbirth or weak calves and neonatal mortality, infertility [6]. In humans, Brucella spp. infection causes a febrile disease that may be associated with a broad spectrum of symptoms, and it may be fatal in some cases [5,7]. Currently, there are ten spp. described in the genus Brucella. Each one may infect different host spp., but each Brucella spp. has a preference for its host spp., B. melitensis (sheep and goats), B. abortus (cattle), $B$. suis (pigs), B. ovis (rams), B. canis (dogs), B. microti (rodents-Microtus arvalis), B. neotomae (rodents - Neotoma lepida), B. pinnipedialis (pinnipeds), B. ceti (cetacea), and B. inopinata (originally isolated from a human patient, but its preferential host is not known) [8,9]. Three of this Brucella spp. can be subdivided in biotypes $[10,11]$.

Therefore, three biotypes (1-3) have been identified in B. melitensis; eight biotypes (1-7,9) in B. abortus, and five biotypes (1-5) in B. suis [12]. All Brucella spp. are considered potentially pathogenic for humans, with the exceptions of $B$. neotomae, B. microti, and B. ovis $[6,9]$.

A precise diagnosis of Brucella spp. infection is important for the control of the disease in animals and consequently in man. Clinical diagnosis is based usually on the history of reproductive failures in livestock, but it is a presumptive diagnosis [13] that must be confirmed by laboratory methods $[13,14]$. The "gold standard" in the diagnosis of brucellosis is bacterial isolation from blood or bone marrow specimens that requires long cultivation periods (4 to 7 days up to 40 days) and often the blood cultures are unsuccessful [15]. Serological tests, such as serum agglutination test (SAT), rose Bengal plate test (RBPT), complement fixation test (CFT), and enzyme-linked immunosorbent assay (ELISA) are still frequently used $[5,16]$. Since the routine identification and differentiation of brucellosis suspected specimens, based on culture isolation and phenotypic characterization, requires biosafety level-3 (BSL-3) protocols for the high risk of laboratoryacquired infections [17], molecular methods have been explored in order to overcome these difficulties. Furthermore, the polymerase chain reaction (PCR)-based assays have shown a higher sensitivity with respect to the standard microbiological assay for the diagnosis of brucellosis [18].

Therefore, the objectives of this paper are to review a diagnostic methods that are used for isolation, screening, monitoring or epidemiological surveillance and complementary or confirmatory for brucellosis in livestock and humans.

\section{Direct Methods for Diagnosis of Brucellosis}

\section{Bacteriological diagnosis}

Isolation of the organism is considered the gold standard diagnostic method for brucellosis since it is specific and allows biotyping of the isolate, which is relevant under an epidemiological point of view $[10,19]$. However, in spite of its high specificity, culture of Brucella spp. is challenging. Brucella spp. is a fastidious bacterium and requires rich media for primary cultures. Furthermore, its isolation requires a large 
number of viable bacteria in clinical samples, proper storage and quick delivery to the diagnostic laboratory $[9,20]$.

Contamination of clinical samples is a complicating factor for Brucella spp. isolation. Therefore, the use of nutrient-rich media supplemented with antibiotics (Polymixin B 5,000 UI/L; bacitracin 25,000 UI/L; cyclohexamide $100 \mathrm{mg} / \mathrm{L}$; nalidixic acid $5 \mathrm{mg} / \mathrm{L}$; nystatin $100,000 \mathrm{UI} / \mathrm{L}$ and vancomycin $20 \mathrm{mg} / \mathrm{L}$ ) is used to inhibit growth of contaminants that may prevent isolation of Brucella spp. [21].

Another limiting factor for culturing Brucella spp. is the requirement for appropriate laboratory conditions and personnel training so the procedure can be performed safely [22]. Brucella spp. is classified as a Biosafety level 3 organism, whose manipulation should be performed in biosafety level-3 laboratories [23]. Importantly, brucellosis is one of the most common accidental laboratory infections, particularly in research laboratories [24,25].

Samples for Brucella spp. isolation from cattle include fetal membranes, particularly the placental cotyledons where the number of organisms tends to be very high. In addition, fetal organs such as the lungs, bronchial lymph nodes, spleen and liver, as well as fetal gastric contents, milk, vaginal secretions and semen are samples of choice for isolation $[23,26]$. Vaginal secretions should be sampled after abortion or parturition, preferably using a swab with transporter medium, allowing isolation of the organism up to six weeks post parturition or abortion [13]. Milk samples should be a pool from all four mammary glands. Non- pasteurized dairy products can also be sampled for isolation $[13,23]$.

Samples of choice in slaughterhouses include mammary, iliac, pharyngeal, parotids and cervical lymph nodes, and spleen. Samples must be immediately sent to the laboratory, preferentially frozen at $-20^{\circ} \mathrm{C}$, and they must be identified as suspect of Brucella spp. infection [13]. Vaginal swabs, semen and seminal fluid have low numbers of viable organisms, and therefore isolation is more difficult, often resulting in false negative results. Enrichment media containing selected antibiotics can improve the sensitivity in these cases [21,27].

Brucella spp. colonies are elevated, transparent, convex, with intact borders, smooth, and a brilliant surface. The colonies have a honey color under transmitted light. Optimal temperature for culture is $37^{\circ} \mathrm{C}$, but the organism can grow under temperatures ranging from $20^{\circ} \mathrm{C}$ to $40^{\circ} \mathrm{C}$, whereas optimal $\mathrm{pH}$ ranges from 6.6 to 7.4. Some Brucella spp. requires $\mathrm{CO}_{2}$ for growth. Typical colonies appears after 2 to 30 days of incubation, but a culture can only be considered negative when there are no colonies after 2 to 3 weeks of incubation [28]. False negative results should be considered in the absence of bacterial growth since the sensitivity of culture is low [13].

Usually, solid media such as dextrose agar, tryptose agar, and trypticase soy agar, are recommended for primary isolation of Brucella, but some species, i.e., B. ovis and B. canis require addition of $5-10 \%$ of sterile bovine or equine serum to the culture media. In the case of blood or milk, biphasic media such as Castañeda's medium is recommended for improving sensitivity [13].

\section{Immunohistochemistry}

Immunohistochemistry is an alternative technique for direct diagnosis of Brucella spp. infection. It has been extensively used in studies of pathogenesis and diagnosis of brucellosis, allowing in situ localization of the organisms within Brucella induced lesions [29]. An advantage of this technique is that it does not require viable bacteria and allow retrospective studies [30]. Although immunohistochemistry is simple, several factors may affect the result, including the fixation protocol and selection of the primary antibody [31].

\section{Molecular methods for Brucella species genotyping}

Molecular techniques are important tools for diagnosis and epidemiologic studies, providing relevant information for identification of species and biotypes of Brucella spp., allowing differentiation between virulent and vaccine strains $[32,33]$. Molecular detection of Brucella spp. can be done directly on clinical samples without previous isolation of the organism. In addition, these techniques can be used to complement results obtained from phenotypic tests [34].

Polymerase chain reaction (PCR) and/its variants, based on amplification of specific genomic sequences of the genus, species or even biotypes of Brucella spp., are the most broadly used molecular technique for brucellosis diagnosis [10]. The technique is chosen based on the type of biological sample and the goal, i.e., diagnosis or molecular characterization or epidemiological survey. Most of the molecular diagnostic methods for brucellosis have sensitivity ranging from $50 \%$ to $100 \%$ and specificity between $60 \%$ and $98 \%$. The DNA extraction protocol, type of clinical sample, and detection limits of each protocol, are factors that can influence the efficiency of the technique [35].

Since the routine identification and differentiation of brucellosis suspected specimens, based on culture isolation and phenotypic characterization, requires Biosafety level-3 (BSL-3) protocols for the high risk of laboratory-acquired infections [17], molecular methods have been explored in order to overcome these difficulties. Furthermore, the PCR-based assays have shown a higher sensitivity with respect to the standard microbiological assay for the diagnosis of brucellosis [18].

\section{Multiplex polymerase chain reaction typing}

Several multiplex PCRs which identify the genus Brucella at the species level and partly at the biovar level using different primer combinations have been reported. The first multiplex PCR, called AMOS PCR assay (AMOS is an acronym from "abortus-melitensisovis-suis"), comprised five oligonucleotide primers for the identification of selected biovars of four species of Brucella. The assay exploited the polymorphism arising from species-specific localization of the genetic element IS711 in the Brucella chromosome. Identity was determined by the size of the product amplified from primers hybridizing at various distances from the element.

This method could identify three biovars $(1,2$, and 4$)$ of $B$. abortus, allthree biovars of $B$. melitensis, all B. ovis biovars and biovar 1 of $B$. suis. An abbreviated multiplex AMOS PCR assay based on three additional primers was developed to differentiate $B$. abortus vaccine strains S19 and RB51 from field strains [36]. In 2005 the finding of a deletion next to one of the IS711 copies in $B$. abortus biovars 5, 6, 9 and in some field strains of biovars 3 of $B$. abortus has allowed to design and add a specific primer to the eight primer mixtures of AMOS PCR, allowing enhancing the discrimination power of this assay.

A random amplified polymorphic DNA (RAPD-PCR) was used in order to develop a multiplex PCR that uses the AMOS primers, additional specific loci of the insertion element IS711, and other unique insertions and deletions. This novel PCR assay differentiates 
between all presently recognized Brucella species, including the recently described species $B$. ceti (formerly named 'B. maris' or ' $B$. cetaceae), $B$. pinnipedialis (formerly named ' $B$. maris' or ' $B$. pinnipediae), and $B$. microti, including some more recently described strains of the latter species [37-39], and also allows accurate differentiation of certain biovars of B. abortus and B. suis [40].

\section{Real-time PCR}

Real-time PCR is more rapid and more sensitive than conventional PCR. It does not require post amplification handling of PCR products, thereby reducing the risk of laboratory contamination and falsepositive results. Real-time PCR assays have been recently described in order to test Brucella cells [41], urine [42], blood, and paraffinembedded tissues [43].

Three separate real-time PCRs were developed to specifically identify seven biovars of $B$. abortus, three biovars of $B$. melitensis and biovar one of $B$. suis using fluorescence resonance energy transfer. The upstream primers used in these real-time PCRs derived from the insertion element, IS711 whereas the reverse primer and FRET probes are selected from unique species or biovar-specific chromosomal loci. Sensitivity of $B$. abortus-specific assay was as low as $0.25 \mathrm{pg}$ DNA corresponding to 16-25 genome copies and similar detection levels were also observed for B. melitensis and B. suis-specific assays [41].

\section{High resolution melt}

The development of a molecular technique which utilizes real-time PCR followed by high-resolution melt (HRM) curve analysis to reliably type members of this genus has been described by Winchell et al. [44]. The assay targeted discriminating loci within the genomes of Brucella spp. and through the dissociation curve analysis allowing the accurately identification of Brucella isolates at the species level and of unusual Brucella isolates such as $\mathrm{BO} 1$ and $\mathrm{BO} 2$. This assay also proved successful for discriminating $B$. suis from $B$. canis, but was unable to accurately differentiate a $B$. suis biovar 4 from $B$. canis. However, this particular $B$. suis biovar has previously been reported to exhibit a genotypic pattern identical to $B$. canis, and it is still debated as to whether this is truly a unique biovar of $B$. suis $[45,46]$.

\section{Restriction fragment length polymorphism based approaches}

Polymerase chain reaction (PCR)-restriction fragment length polymorphism (PCR-RFLP) is a common approach for typing of Brucella spp., providing a good tool for taxonomic, epidemiological, evolutionary and diagnostic studies. The method has especially been utilized in studies of various outer membrane protein (omp) genes [47].

\section{Single nucleotide polymorphisms typing}

Single nucleotide polymorphisms (SNPs) represent powerful markers that allow accurately describing the phylogenetic framework of a species, particularly in a genetically conserved group as Brucella. The approach is based on a series of discrimination assays interrogating SNPs that shown to be specific to a particular Brucella spp. Scott et al. [48] described the use of SNPs in order to develop a multiplex SNP detection assay, based on primer extension technology that can rapidly and unambiguously identify an isolate as a member of one of the six classical Brucella spp. or as a member of the recently identified marine mammal group.

An alternative approach based on minor groove binding protein (MGB) probes applied on a real-time PCR platform was described $[49,50]$.

The assay distinguishes all members of the classical species, but the differentiation of $B$. suis and $B$. canis was difficult as no B. suis specific SNP has been identified. However, as a specific $B$. canis SNP has been identified [45], it is possible a discrimination with $B$. suis/B. canis specific SNP and the B. canis specific SNP [12].

\section{Matrix-assisted laser desorption ionization time-of-flight mass spectrometry}

Bacterial identification based on peptidic spectra obtained by matrix-assisted laser desorption ionization time-of-flight (MALDITOF) mass spectrometry was proposed 30 years ago. This method represents a new diagnostic tool in established microbiological laboratories [51]. Databases have been developed that include the main pathogenic microorganisms, thus allowing the use of this method in routine bacterial identification from plate culture. Recently, to identify Brucella species a reference library was constructed using 12 Brucella strains. With this 'Brucella library' discrimination was not possible to the species level [52].

\section{Tandem repeat based typing}

In the last years the availability of microbial genome sequences has facilitated the development of multilocus sequence-based typing approaches such as multiple locus variable number of tandem repeats (VNTR) analysis (MLVA). The VNTR, allelic hyper variability related to variation in the number of tandemly repeated sequences observed at several genomic loci in the Brucella genomes, were used for the discrimination of bacterial species that display very little genomic diversity.

The first application of VNTR based typing to Brucella was the HOOF-Prints scheme (Hyper Variable Octomeric Oligonucleotide Finger-Prints) published by Bricker et al. [53]. The approach was based on a comparison of the newly completed genome sequences of $B$. suis and $B$. melitensis along with a draft $B$. abortus sequence which identified an eight base pair tandem repeat sequence at nine distinct genomic loci [12].

\section{Indirect Methods for Diagnosis of Brucellosis}

\section{Serological tests}

Serological tests are crucial for laboratory diagnosis of brucellosis since most of control and eradication programs rely on these methods. Inactivated whole bacteria or purified fractions (i.e., lipopolysaccharide or membrane proteins) are used as antigens for detecting antibodies generated by the host during the infection. Antibodies against smooth Brucella species (e.g., B. abortus, $B$. melitensis, and $B$. suis) cross react with antigen preparations from $B$. abortus, whereas antibodies against rough Brucella species (e.g., $B$. ovis and $B$. canis) cross react with antigen preparations from $B$. ovis [14].

Although several serological methods are currently available, these tests can be classified as screening tests (e.g., buffered antigen plate agglutination-BPAT), monitoring or epidemiological surveillance tests 
$10.4172 / 2157-7579.1000323$

Page 4 of 8

(e.g., milk ring test), and complementary or confirmatory tests (e.g., 2 mercaptoethanol, complement fixation, ELISAs, and fluorescence polarization assay). Selection of a given test should take into account the species affected as well as local regulations $[13,14]$.

\section{Standard slow agglutination tube test}

Standard slow agglutination tube test (SAT), which was the first developed serological test for diagnosis of brucellosis, is based on bacterial antigen agglutination, particularly by $\operatorname{IgM}$ under neutral $\mathrm{pH}$. This test has low specificity, and therefore it is not recommended $[13,14,53]$.

\section{Milk ring test}

The milk ring test is based on agglutination of antibodies secreted into the milk. This test allows screening of large number of cattle by using milk samples from tanks or pools from several cows. This test is useful for monitoring cattle herds or areas free of brucellosis so it is classified as surveillance or monitoring test [53]. Importantly, the number of false positive results is proportional to the number of cows secreting acidic milk due to colostrums or mastitis [53]. A positive result indicates the presence of infected cattle in the herd so the test should be followed by individual serological test in the entire herd.

\section{2-Mercaptoethanol}

The 2-mercaptoethanol is a confirmatory test that allows selective quantification of IgG anti-Brucella due to inactivation of IgM in the test sample. Production of IgG is usually associated with chronic infection, and therefore, a positive result with this test is a strong indicator of brucellosis. However, this test has some drawbacks including the toxicity of mercaptoethanol, which requires a fume hood for its manipulation, and the possibility of IgG degradation caused by the 2-mercaptoethanol, which may result in false negative results [13]. Sensitivity of the 2-mercaptoethanol test varies from 88.4 and $99.6 \%$, and its specificity from 91.5 and $99.8 \%$ [54].

\section{Complement fixation test}

Due to its high accuracy, complement fixation is used as confirmatory test for B. abortus, B. melitensis, and B. ovis infections and it is the reference test recommended by the OIE for international transit of animals [55,56]. However, this method has some disadvantages such as high cost, complexity for execution, and requirement for special equipment and trained laboratory personnel. In addition, the test presents limitations with hemolysed serum samples or serum with anti-complement activity of some sera, and the occurrence of prozone phenomena [54]. Sensitivity of complement fixation ranges from 77.1 to $100 \%$ and its specificity from 65 to $100 \%$ $[56,57]$.

\section{Rose bengal plate test}

The rose bengal test (RBT) is a rapid, slide-type agglutination assay performed with a stained B. abortus suspension at $\mathrm{pH}$ of 3.6-3.7 and plain serum. Its simplicity made it an ideal screening test for small laboratories with limited resources. The drawbacks of RBT include: low sensitivity particularly in chronic cases, relatively low specificity in endemic areas and prozones make strongly positive sera appear negative in RBT [58]. The overall sensitivity is $92.9 \%$, so the use of RBT should be considered carefully in endemic areas, particularly in individuals exposed to brucellosis and those having history of Brucella infection [59]. Rose Bengal plate test [RBT] is an agglutination test that is based on reactivity of antibodies against smooth lipopolysaccharide (LPS). As sensitivity is high, false negative results are rarely encountered. To increase specificity, the test may be applied to a serial dilution (1:2 through 1:64) of the serum samples [60]. The present World Health Organization (WHO) guidelines recommend the confirmation of the RBT by other assays such as serum agglutination tests $[60,61]$.

\section{Enzyme linked immunosorbent assay}

Enzyme linked immunosorbent assay (ELISA) has become popular as a standard assay for the diagnosis of brucellosis, serologically. It measures IgG, IgA and IgM antibodies and this allows a better interpretation of the clinical situation. The diagnosis of brucellosis is based on the detection of antibodies against the smooth LPS. Detection of IgG antibodies is more sensitive than detection of IgM antibodies for diagnosing cases of brucellosis but specificity is comparable [61-63]. Compared to the conventional agglutination methods, ELISA is more sensitive in acute and chronic cases of brucellosis and it offers a significant diagnostic advantage in the diagnosis of brucellosis in endemic areas. For case detection and an accurate diagnosis of suspected cases, the combination of ELISA IgM and IgG tests should be used as this combination of laboratory tests has been shown to be the most efficient technique in the detection and diagnosis of brucellosis.

For follow-up and monitoring of prognosis, ELISA Ig M and 2mercapto ethanol (2-MET) are more promising [64,65].

Enzyme linked immunosorbent assay (ELISA) is an excellent method for screening large populations for Brucella antibodies and for differentiation between acute and chronic phases of the disease [66]. It is the test of choice for complicated, local or chronic cases particularly when other tests are negative while the case is under high clinical suspicion. It can reveal total and individual specific immunoglobulins (IgG, IgA and IgM) within 4-6 hours with high sensitivity and specificity. In addition to the detection of immunoglobulin classes, ELISA can also detect Brucella-specific IgG subclasses and other Brucella immunoglobulins such as IgE [61].

The indirect ELISA (i-ELISA) has been used for serologic diagnosis of brucellosis in sheep, goats and pigs. It has also been used for diagnosis using serum or milk from cattle $[66,67]$. O ELISA-i has been usually used for smooth LPS Brucella spp., and it is sensitive and specific for $B$. abortus or $B$. melitensis, but it is not capable of differentiating antibodies induced by the vaccine strains S19 or Rev1 $[68,69]$. Sensitivity of i-ELISA varies from 96 to $100 \%$ and its specificity from $93.8 \%$ and $100 \%[56,70]$.

The competitive ELISA (c-ELISA) with smooth Brucella LPS as antigen is used for detection of anti-Brucella in serum samples from cattle, sheep, goats, and pigs. This test is capable of differentiating vaccine antibody response from actual infections, and its sensitivity varies from 92 to $100 \%$, whereas the specificity ranges from 90 and $99 \%[57,71]$.

\section{Fluorescence polarization assay}

The fluorescence polarization assay (FPA) was initially developed for testing serum. However, the technology has been extended to testing whole blood and milk samples from individual animals. 
Page 5 of 8

Fluorescence polarization assay (FPA) is based on the rotational differences between a small soluble antigen molecule in solution and the antigen molecule complex with its antibody. It measures the size of a fluorescent tagged molecule such as an antigen. The utilization of the O-side chain of LPS from Brucella species has shown encouraging results. The test is a valuable alternative to conventional serological tests.

Sensitivity of FPA is $96 \%$ for culture-confirmed human brucellosis and specificity is about $98 \%[60,72]$. The fluorescence polarization assay has been used for the diagnosis of Brucella spp. infection in man [73] and several animal species, using serum, milk or whole blood in EDTA. This test can be performed under field conditions [14]. Sensitivity of the fluorescence polarization assay varies from 87.5 and $100 \%$, and specificity from 84 to $100 \%$ [71], which is similar to the levels obtained with c-ELISA [56].

\section{Agar gel immunodiffusion test}

The agar gel immunodiffusion test is based on precipitation of the antigen-antibody complex. This method is often used for the diagnosis of $B$. ovis infection. This test has a low cost, it is easily performed and it has sensitivity levels that are comparable to complement fixation. However, it has some disadvantages such as a marked decrease in sensitivity in chronic infections and high variability of the quality of commercially available antigens. Therefore, it is highly advisable to perform complementary diagnostic techniques such as PCR [74]. Sensitivity of the agar gel immunodiffusion test varies from 50 to $92.7 \%$ and the specificity from 94.3 and $100 \%$ [70,75] (Table 1).

\begin{tabular}{|l|l|l|l|}
\hline Species & Screening tests & Confirmatory test & Reference \\
\hline B. abortus & BPAT,MRT & 2ME,CF,ELISAc & OIE [53] \\
\hline B. melitensis & BPAT & BPAT,CF & OIE [55] \\
\hline B. suis & BPAT & 2ME,CF,AGIT,ELISAc & Di Febo et al. [67] \\
\hline B. canis & - & 2ME,AGIT,ELISAi & Ebani et al. [76] \\
\hline B. ovis & - & CF, AGIT, i-ELISA & Gall et al. [66]; OIE [55] \\
\hline
\end{tabular}

Table 1: Screening and confirmatory tests commonly used in the serological diagnosis of Brucella spp. infection. 2ME-2-mercaptoethanol, AGITAgar gel immunodiffusion test, BPAT-Buffered antigen plate agglutination, CF-Complement fixation, ELISAi-Indirect ELISA, ELISAcCompetitive ELISA, FPA-Fluorescence polarization assay, MRT-Milk ring test.

\section{Coombs test}

This is the most suitable and sensitive test for confirmation of relapsing patients with persistent disease [60]. It is an extension of the SAT test i.e., if the SAT test yields negative results due to the presence of blocking antibodies, Coombs test may be used instead. Agglutination can be determined visually, as for SAT, by using an agglutinoscope or a drop on a slide examined under the microscope [61]. Coombs test is used for detection of incomplete, blocking or nonagglutinating IgG. It is time consuming, technically difficult, requires skilled personnel and not routinely performed in clinical laboratories. It is good for complicated and chronic cases but misses about $7 \%$ of cases compared with ELISA [76,77].

\section{Dipstick assay}

The IgM dipstick assay is one of the tests that have been adapted to detect IgM antibodies to the smooth LPS. The assay has shown high sensitivity for patients with disease lasting less than 3 months $[78,79]$. IgM dipstick assay offers higher sensitivity and easier manipulation than IgM ELISA to detect IgM antibodies to Brucella species and improves the interpretation of results thus establishing cut-off points. IgM dipstick assay could be used as a rapid and simple alternative to the ELISA IgM for the serodiagnosis of patients with acute brucellosis.

The combined results of SAT and IgM dipstick assays can provide an indication of the stage of disease for those patients in whom the onset of clinical manifestations is not known [80].

\section{Immunocapture agglutination test; Brucella Capt}

Recently, new immunocapture agglutination for anti-Brucella (BCAP) assay has been developed to detect agglutinating and nonagglutinating antibodies with high sensitivity [81].

It is based on the sandwich ELISA system, where a microwell is covered with Coombs antibodies against human origin IgG, IgA and IgM antibodies. This Brucella agglutination test occurs in a microwell and is performed with Coombs antibodies and determines the 3 antibodies that form against brucellosis. It has been suggested as a possible substitute for Coombs test and a better marker for disease activity [81].

Compared to Coombs test, it has similar sensitivity and specificity but both can remain positive for long time after treatment in cured patients. BCAP determines blocking antibodies at diagnosis and during follow up for patients having brucellosis. It is easier to carry out in 24 hours without a second step necessary as in Coombs test [82]. In comparison with other tests: it is more complex, expensive and slow. It can hardly replace rapid screening tests such as RBT and dipstick as a screening or first diagnostic test. However, it could help to diagnose disease in patients with longstanding evolution of brucellosis that is not detected by SAT. So, like Coombs test, Brucella Capt which is based on the immunocapture-agglutination of the total anti-Brucella antibodies, could be a second level serological test $[60,79]$.

\section{Lateral flow assay}

An immunochromatographic Brucella IgM / IgG lateral flow assay is a simplified version of the ELISA test and has a great potential as a 


\section{(10.4172/2157-7579.1000323}

Page 6 of 8

rapid point-of-care assay. The test has high sensitivity and specificity for Brucella IgM and IgG. It uses a drop of blood obtained by finger prick. It can be done as a bedside procedure. So it is a rapid and a simple diagnostic test that is also easy to interpret [60].

\section{Rapid slide agglutination test}

Since routine brucellosis diagnosis does not include B. canis investigation, infection with this species may be more widespread than is currently suspected. The rapid slide agglutination assay test (RSAT) could be a suitable screening test for the diagnosis of human brucellosis and a supplementary technique, such as ELISA, performed on all positive RSAT samples that were negative by $B$. abortus antigen could ensure diagnostic specificity and confirm the diagnosis. It is recommended to use MAT and 2-ME/RSAT to check sera of all patients, who have symptoms of brucellosis but are negative for brucellosis using a smooth Brucella antigen [83,84].

\section{Brucellin allergic skin test}

The skin test is an allergic test that detects the specific cellular immune response induced by Brucella spp. infection. The injection of brucellergene, a protein extract of a rough strain of Brucella spp., is followed by a local inflammatory response in a sensitized animal. This delayed type hypersensitivity reaction is measured by the increase in skin thickness at the site of inoculation. This test is highly efficient in discriminating between true brucellosis cases and false positive serological reactions. The skin test is highly specific but its weak sensitivity makes it a good test for herds but not for individual certification. It cannot discriminate between infection and vaccination [85]. Pouillot et al. [86] made an assessment of the diagnostic value of the Brucellin allergic skin test (AST) in a brucellosis false positive serological reaction and reported that allergenic skin test is to be more specific than RBT and CFT. Therefore, this test could be used as a confirmatory test on cattle non-vaccinated against brucellosis. This test is prescribed as an alternative test by the OIE [53].

\section{Conclusion}

A precise diagnosis of Brucella spp. infection is, important for the control of the disease in animals and consequently in man. Clinical diagnosis is based usually on the history of reproductive failures in livestock, but it is a presumptive diagnosis that must be confirmed by laboratory methods. Direct diagnosis of brucellosis involves bacteriolo gical, immunohistochemis-try and molecular methods. Under an epidemiological point of view, bacterial isolation from different specimen is more relevant, since it is more specific and allows biotyping of the isolate but it requires BSL-3 protocols for the high risk of laboratory-acquired infections. For retrospective studies, immunohistochemistry allows in situ localization of the organisms within Brucella induced lesion since it does not require viable bacteria. Molecular techniques are important tools for diagnosis and epidemiologic studies, providing relevant information for identification of species and biotypes of Brucella spp., allowing differentiation between virulent and vaccine strains. Serological methods are among the well-established indirect laboratory diagnosis of brucellosis since most of control and eradication programs rely on these methods while brucellin allergic skin test could be used as a confirmatory test on animal non-vaccinated against brucellosis and more specific than RBT and CFT.

\section{References}

1. Pappas G, Papadimitriou P (2007) Challenges in Brucella bacteraemia. Int J Antimicrob Agents 30 Suppl 1: S29-31.

2. Wyatt HV (2005) How Themistocles Zammit found Malta Fever (brucellosis) to be transmitted by the milk of goats. J R Soc Med 98: 451-454.

3. Sriranganathan N, Seleem N, Olsen C, Samartino E, Whatmore M, et al. (2009) Brucella, In: Nene V, Kole C (Eds) : Genome mapping and genomics in animal-associated microbes. Springer-Verlag, Berlin, pp: 1-64.

4. Godfroid J, Cloeckaert A, Liautard JP, Kohler S, Fretin D, et al. (2005) From the discovery of the Malta fever's agent to the discovery of a marine mammal reservoir, brucellosis has continuously been a re-emerging zoonosis. Vet Res 36: 313-326.

5. Pal M (2007) Zoonoses. (2nd Edn) Satyam Publishers, Jaipur, India, pp: 98-99.

6. Xavier N, Costa A, Paixão A, Santos L (2009) Genus Brucella and clinical manifestations. Ciência Rural 39: 2252-2260.

7. Cutler SJ, Whatmore AM, Commander NJ (2005) Brucellosis--new aspects of an old disease. J Appl Microbiol 98: 1270-1281.

8. de Jong MF, Tsolis RM (2012) Brucellosis and type IV secretion. Future Microbiol 7: 47-58.

9. Hadush A, Pal M (2013) Brucellosis: An infectious re-emerging bacterial zoonosis of global importance. Int J Livestock Health 3: 28-34.

10. Bricker BJ (2002) Diagnostic strategies used for the identification of Brucella. Vet Microbiol 90: 433-434.

11. Ocampo-Sosa AA, Agüero-Balbín J, García-Lobo JM (2005) Development of a new PCR assay to identify Brucella abortus biovars 5,6 and 9 and the new subgroup $3 \mathrm{~b}$ of biovar 3. Vet Microbiol 110: 41-51.

12. Whatmore AM (2009) Current understanding of the genetic diversity of Brucella, an expanding genus of zoonotic pathogens. Infect Genet Evol 9: 1168-1184.

13. Poester P, Nielsen K, Samartino E (2010) Diagnosis of brucellosis. Open Vet Sci J 4: 46-60.

14. Nielsen K (2002) Diagnosis of brucellosis by serology. Vet Microbiol 90: 447-459.

15. Rich M, Bannatyne RM, Memish ZA (2000) Direct urease test on BACTEC blood cultures: early presumptive diagnosis of brucellosis in an area of endemicity. J Clin Microbiol 38: 1706.

16. Gwida M, Al Dahouk S, Melzer F, Rösler U, Neubauer H, et al. (2010) Brucellosis - regionally emerging zoonotic disease? Croat Med J 51: 289-295.

17. Boschiroli ML, Foulongne V, O'Callaghan D (2001) Brucellosis: a worldwide zoonosis. Curr Opin Microbiol 4: 58-64.

18. Hoover D, Friedlander A (1997) Brucellosis: Medical aspects of chemical and biological warfare. Textbook of Military Medicine pp: 5013-5021.

19. Al Dahouk S, Tomaso H, Nöckler K, Neubauer H, Frangoulidis D (2003) Laboratory-based diagnosis of brucellosis--a review of the literature. Part I: Techniques for direct detection and identification of Brucella spp. Clin Lab 49: 487-505.

20. Seleem MN, Boyle SM, Sriranganathan N (2010) Brucellosis: a reemerging zoonosis. Vet Microbiol 140: 392-398.

21. De Miguel MJ, Marín CM, Muñoz PM, Dieste L, Grilló MJ, et al. (2011) Development of a selective culture medium for primary isolation of the main Brucella species. J Clin Microbiol 49: 1458-1463.

22. Nielsen H, Ewalt R (2004) Bovine brucellosis: In manual of standards for diagnostic tests and vaccines, (5th Edn) OIE, Paris, France, pp: 328-345.

23. Lage P, Poester P, Paixão A, Silva A, Xavier N, et al. (2008) Brucelose bovina: uma atualização. Revista Brasileira de Reprodução Anim 32: 202-212.

24. Singh K (2009) Laboratory-acquired infections. Clin Infect Dis 49: 142-147. 
25. Sam IC, Karunakaran R, Kamarulzaman A, Ponnampalavanar S, Syed Omar SF, et al. (2012) A large exposure to Brucella melitensis in a diagnostic laboratory. J Hosp Infect 80: 321-325.

26. Poester FP, Gonçalves VS, Paixão TA, Santos RL, Olsen SC, et al. (2006) Efficacy of strain RB51 vaccine in heifers against experimental brucellosis. Vaccine 24: 5327-5334.

27. Her M, Cho DH, Kang SI, Cho YS, Hwang IY, et al. (2010) The development of a selective medium for the Brucella abortus strains and its comparison with the currently recommended and used medium. Diagn Microbiol Infect Dis 67: 15-21.

28. Carmichael E, Greene E (1990) Canine brucellosis: In infectious diseases of the dog and cat. Green E (Ed) Philadelphia: WB Saunders, pp: 573-584.

29. Xavier MN, Paixão TA, Poester FP, Lage AP, Santos RL (2009) Pathological, immunohistochemical and bacteriological study of tissues and milk of cows and fetuses experimentally infected with Brucella abortus. J Comp Pathol 140: 149-157.

30. Santos L, Peixoto D, Serakides R, Costa M, Martins E (1998) Detección de Brucella abortus (muestra B19) por el complejo inmunoenzimático avidina-biotinaperoxidasaenel testículo y en el epidídimo de bovinos inoculados experimentalmente. Archives Reproductive Animal, pp: 34-41.

31. Ramos-Vara JA (2005) Technical aspects of immunohistochemistry. Vet Pathol 42: 405-426.

32. Le Flèche P, Jacques I, Grayon M, Al Dahouk S, Bouchon P, et al. (2006) Evaluation and selection of tandem repeat loci for a Brucella MLVA typing assay. BMC Microbiol 6: 9.

33. López-Goñi I, García-Yoldi D, Marín M, De-Miguel J, Muñoz M, et al. (2008) Evaluation of a multiplex PCR assay (Bruce-ladder) for molecular typing of all Brucella species, including the vaccine strains. J Clin Microbiol 46: 3484-3487.

34. Bricker BJ (2002) PCR as a diagnostic tool for brucellosis. Vet Microbiol 90: 435-446.

35. Mitka S, Anetakis C, Souliou E, Diza E, Kansouzidou A (2007) Evaluation of different PCR assays for early detection of acute and relapsing brucellosis in humans in comparison with conventional methods. J Clin Microbiol 45: 1211-1218.

36. Ewalt DR, Bricker BJ (2000) Validation of the abbreviated Brucella AMOS PCR as a rapid screening method for differentiation of Brucella abortus field strain isolates and the vaccine strains, 19 and RB51. J Clin Microbiol 38: 3085-3086.

37. Scholz HC, Hubalek Z, Sedlácek I, Vergnaud G, Tomaso H, et al. (2008) Brucella microti sp. nov., isolated from the common vole Microtus arvalis. Int J Syst Evol Microbiol 58: 375-382.

38. Scholz HC, Hubalek Z, Nesvadbova J, Tomaso H, Vergnaud G, et al. (2008) Isolation of Brucella microti from soil. Emerg Infect Dis 14 1316-1317.

39. Scholz HC, Hofer E, Vergnaud G, Le Fleche P, Whatmore AM, et al (2009) Isolation of Brucella microti from mandibular lymph nodes of red foxes, Vulpes vulpes, in lower Austria. Vector Borne Zoonotic Dis 9: 153-156.

40. Huber B, Scholz HC, Lucero N, Busse HJ (2009) Development of a PCR assay for typing and subtyping of Brucella species. Int J Med Microbiol 299: 563-573.

41. Redkar R, Rose S, Bricker B, DelVecchio V (2001) Real-time detection of Brucella abortus, Brucella melitensis and Brucella suis. Mol Cell Probes 15: 43-52.

42. Queipo-Ortuño MI, Colmenero JD, Reguera JM, García-Ordoñez MA Pachón ME, et al. (2005) Rapid diagnosis of human brucellosis by SYBR Green I-based real-time PCR assay and melting curve analysis in serum samples. Clin Microbiol Infect 11: 713-718.

43. Kattar M, Zalloua A, Araj F, Samaha-K, foury J, et al. (2007) Development and evaluation of real-time polymerase chain reaction assays on whole blood and paraffin-embedded tissues for rapid diagnosis of human brucellosis. Diagn Microbiol Infect Dis 59: 23-32.
44. Winchell JM, Wolff BJ, Tiller R, Bowen MD, Hoffmaster AR (2010) Rapid identification and discrimination of Brucella isolates by use of real-time PCR and high-resolution melt analysis. J Clin Microbiol 48: 697-702.

45. Whatmore AM, Perrett LL, MacMillan AP (2007) Characterisation of the genetic diversity of Brucella by multilocus sequencing. BMC Microbiol 7: 34 .

46. Huynh Y, Ert V, Hadfield T, Probert S, Bellaire H (2008) Multiple locus variable number tandem repeat (VNTR) analysis (MLVA) of Brucella spp. identifies species specific markers and insights into phylogenetic relationships. Humana Press, Totowa, NJ 47-54.

47. Al-Dahouk S, Tomaso H, Prenger-Berninghoff E, Splettstoesser D, Scholz C (2005) Identification of Brucella species and biotypes using polymerase chain reaction restriction fragment length polymorphism (PCR-RFLP). Crit Rev Microbiol 31: 191-196.

48. Scott C, Koylass S, Stubberfield R, Whatmore M (2007) Multiplex assay based on single-nucleotide polymorphisms for rapid identification of Brucella isolates at the species level. Appl Environ Microbiol 73: 7331-7337.

49. Foster JT, Okinaka RT, Svensson R, Shaw K, De BK, et al. (2008) Realtime PCR assays of single-nucleotide polymorphisms defining the major Brucella clades. J Clin Microbiol 46: 296-301.

50. Gopaul KK, Koylass MS, Smith CJ, Whatmore AM (2008) Rapid identification of Brucella isolates to the species level by real time PCR based single nucleotide polymorphism (SNP) analysis. BMC Microbiol 8: 86.

51. Seng P, Drancourt M, Gouriet F, La-Scola B, Fournier E (2009) Ongoing revolution in bacteriology: Routine identification of bacteria by matrixassisted laser desorption ionization time-of-flight mass spectrometry. Clin Infect Dis 49: 543-551.

52. Ferreira L, Vega Castaño S, Sánchez-Juanes F, González-Cabrero S, Menegotto F, et al. (2010) Identification of Brucella by MALDI-TOF mass spectrometry. Fast and reliable identification from agar plates and blood cultures. PLoS One 5: e14235.

53. OIE (2009) Bovine brucellosis in terrestrial manual.

54. Nielsen K, Gall D, Smith P, Balsevicius S, Garrido F, et al. (2004) Comparison of serological tests for the detection of ovine and caprine antibody to Brucella melitensis. Rev Sci Tech 23: 979-987.

55. OIE (2009) Bovine epididymitis (B. ovis) in terrestrial manual.

56. Gall D, Nielsen K, Forbes L, Cook W, Leclair D, et al. (2001) Evaluation of the fluorescence polarization assay and comparison to other serological assays for detection of brucellosis in cervids. J Wildlife Dis 37: 110-118.

57. Perrett LL, McGiven JA, Brew SD, Stack JA (2010) Evaluation of competitive ELISA for detection of antibodies to Brucella infection in domestic animals. Croat Med J 51: 314-319.

58. Díaz R, Casanova A, Ariza J, Moriyón I (2011) The Rose Bengal Test in human brucellosis: a neglected test for the diagnosis of a neglected disease. PLoS Negl Trop Dis 5: e950.

59. Ruiz-Mesa D, Sanchez-Gonzalez J, Reguera M, Martin L, Lopez-Palmero S (2005) Rose Bengal test: Diagnostic yield and use for the rapid diagnosis of human brucellosis in emergency departments in endemic areas. Clin Microbiol Infect 11: 221-225.

60. Christopher S, Umapathy BL, Ravikumar KL (2010) Brucellosis: review on the recent trends in pathogenicity and laboratory diagnosis. J Lab Physicians 2: 55-60.

61. Araj GF (2010) Update on laboratory diagnosis of human brucellosis. Int J Antimicrob Agents 36 Suppl 1: S12-17.

62. Sathyanarayan S, Suresh S, Krishna S, Mariraj J (2011) A comparative study of agglutination tests, blood culture and ELISA in the laboratory diagnosis of human brucellosis. Int J Biol Med Res 2: 569-572.

63. Agasthya S, Isloor S, Krishnamsetty P (2012) Seroprevalence study of human brucellosis by conventional tests and indigenous indirect enzymelinked immunosorbent assay. Sci World J 1: 1-5.

64. Mantur B, Parande A, Amarnath S, Patil G, Walvekar R, et al. (2010) ELISA versus conventional methods of diagnosing endemic brucellosis. Am J Trop Med Hyg 83: 314-318. 
Citation: Geresu MA, Kassa GM (2016) A Review on Diagnostic Methods of Brucellosis. J Veterinar Sci Techno 7: 323. doi:

65. Asaad AM, Alqahtani JM (2012) Serological and molecular diagnosis of human brucellosis in Najran, Southwestern Saudi Arabia. J Infect Public Health 5: 189-194.

66. Gall D, Nielsen K, Vigliocco A, Smith P, Perez B, et al. (2003) Evaluation of an indirect-linked immunoassay for presumptive serodiagnosis of B. ovis in sheep. Small Rum Res 48: 173-179.

67. Di Febo T, Luciani M, Portanti O, Bonfini B, Lelli R, et al. (2012) Development and evaluation of diagnostic tests for the serological diagnosis of brucellosis in swine. Vet Ital 48: 133-156.

68. Ko KY, Kim JW, Her M, Kang SI, Jung SC, et al. (2012) Immunogenic proteins of Brucella abortus to minimize cross reactions in brucellosis diagnosis. Vet Microbiol 156: 374-380.

69. Lim JJ, Kim DH, Lee JJ, Kim DG, Min W, et al. (2012) Evaluation of recombinant $28 \mathrm{kDa}$ outer membrane protein of Brucella abortus for the clinical diagnosis of bovine brucellosis in Korea. J Vet Med Sci 74: 687-691.

70. Gall D, Nielsen K (2004) Serological diagnosis of bovine brucellosis: a review of test performance and cost comparison. Rev Sci Tech 23: 989-1002.

71. Godfroid J, Nielsen K, Saegerman C (2010) Diagnosis of brucellosis in livestock and wildlife. Croat Med J 51: 296-305.

72. Nielsen K, Gall D (2001) Fluorescence polarization assay for the diagnosis of brucellosis: a review. J Immunoassay Immunochem 22: 183-201.

73. Lucero NE, Escobar GI, Ayala SM, Silva Paulo P, Nielsen K (2003) Fluorescence polarization assay for diagnosis of human brucellosis. J Med Microbiol 52: 883-887.

74. Costa A, Sant'ana M, Carvalho S, Moustacas S, Silva S, et al. (2012) Diagnosis of B. ovis infection by serology and PCR in urine samples from naturally infected rams in the State of Piauí. Arquivo. Brasileiro de Medic. Vet Zootecnia 64: 751-754.

75. Estein SM, Baldi PC, Bowden RA (2002) Comparison of serological test based on outer membrane or internal antigens for detecting antibodies to Brucella ovis in infected flocks. J Vet Diagn Invest 14: 407-411.
76. Ebani VV, Cerri D, Fratini F, Bey RF, Andreani E (2003) Serological diagnosis of brucellosis caused by Brucella canis. New Microbiol 26: 65-73.

77. Sargüzel M, Kayman T, Celik I, Koc N (2011) Comparison of standard tube agglutination, Coombs' and Brucella Capt tests in the diagnosis of brucellosis. New J Med 28: 113-115.

78. Lim L, Richman S (2004) Brucellosis. Infect Dis Clin Pract 12: 7-14.

79. Taleski V (2010) An overview of introducing various laboratory tests for diagnosis of human brucellosis in the republic of Macedonia. Maced J Med Sci 3: 239-245.

80. Clavijo E, Díaz R, Anguita A, García A, Pinedo A, et al. (2003) Comparison of a dipstick assay for detection of Brucella-specific immunoglobulin $\mathrm{M}$ antibodies with other tests for serodiagnosis of human brucellosis. Clin Diagn Lab Immunol 10: 612-615.

81. Odemir M, Feyzioglu B, Kurtoglu MG, Dogan M, Dagi HT, et al. (2011) A comparison of immuncapture agglutination and ELISA methods in serological diagnosis of brucellosis. Int J Med Sci 8: 428-432.

82. Casao MA, Navarro E, Solera J (2004) Evaluation of Brucellacapt for the diagnosis of human brucellosis. J Infect 49: 102-108.

83. Lucero NE, Escobar GI, Ayala SM, Jacob N (2005) Diagnosis of human brucellosis caused by Brucella canis. J Med Microbiol 54: 457-461.

84. Sayan M, Erdenlig S, Stack J, Kilic S, Guducuoglu H, et al. (2011) A serological diagnostic survey for Brucella canis infection in Turkish patients with Brucellosis-like symptoms. Jpn J Infect Dis 64: 516-519.

85. Saegerman C, Vo TK, De Waele L, Gilson D, Bastin A, et al. (1999) Diagnosis of bovine brucellosis by skin test: conditions for the test and evaluation of its performance. Vet Rec 145: 214-218.

86. Pouillot R, Garin-Bastuji B, Gerbier G, Coche Y, Cau C, et al. (1997) The Brucellin skin test as a tool to discriminate false positive serological reactions in bovine brucellosis. Vet Res 28: 365-374. 